Management

Manuscript Number:

Title: COMPARISON OF DIFFERENT APPROACHES FOR THE ESTIMATION OF ODOUR EMISSIONS FROM LANDFILL SURFACES

Article Type: SI:Sanitary Landfilling

Keywords: odour impact assessment; dispersion modelling; surface sampling; wind tunnel; satatic hood; flux chamber.

Corresponding Author: Dr. Laura Capelli, Ph.D.

Corresponding Author's Institution: Politecnico di Milano

First Author: Federico Lucernoni

Order of Authors: Federico Lucernoni; Laura Capelli; Selena Sironi

Abstract: The study addresses the problem of the assessment of odour emissions from landfills. The aim of the project is the research concerning how to quantify odour emissions from landfill surfaces, since there is no evidence of a widely accepted method to evaluate odour emissions from this particular kind of source. Seven different methods have been developed and investigated; these methods can be seen as based on three distinct approaches to the problem, both experimental and computational. The first approach provides to use models for the estimation the landfill gas production, whereby the second and the third approach are based on direct measurement campaigns on the landfill surface, for the determination either of the methane or for the direct measurement of the odour concentration. The methods have then been compared in terms of resulting odour impact by application of a specific atmospheric dispersion model.

Suggested Reviewers: Günther Schauberger

gunther.schaubergerevetmeduni.ac.at

Prof. G. Schauberger has worked in this field and he might be interested in reviewing the paper I am submitting.

Enrico Davoli

enrico.davoliemarionegri.it

E. Davoli has worked in this field and he might be interested in reviewing the paper I am submitting.

Martin Piringer

martin.piringerezamg.ac.at

M. Piringer has worked in this field and he might be interested in reviewing the paper I am submitting. 


\section{Comparison of different approaches for the estimation of odour emissions from landfill surfaces}

Lucernoni, L. Capelli, S. Sironi

The present work addresses the issue of assessment of odour emissions from landfills, an aspect that in recent years has become a very important matter, for researchers and managers as well as for the general public. The aim is to shed some light on the quantification of odour emissions from landfill surfaces, since there is no evidence of a widely accepted methodology. The methods that are here presented can be seen as based on three distinct approaches to the problem, both experimental and computational. The first approach entails the use of specific models for the estimation the landfill gas production, whereby the second and the third approach are based on direct measurement campaigns on the landfill surface, for the determination either of the methane or of the odour concentration. The methods have then been compared in terms of resulting odour impact by application of a specific atmospheric dispersion model.

As novelty of this work and its contributions to the field of olfactometry and odour dispersion modelling, please consider our paper "Comparison of different approaches for the estimation of odour emissions from landfill surfaces" for publication on Waste Management Journal.

The paper was presented during the Sardinia Symposium 2015 and resulted a selected paper considered for publication on Waste Management Journal.

We hope this paper will be of interest for the readers of this journal.

Best regards,

Laura Capelli and Federico Lucernoni 


\section{COMPARISON OF DIFFERENT APPROACHES FOR THE ESTIMATION OF \\ 2 ODOUR EMISSIONS FROM LANDFILL SURFACES}

\section{F. LUCERNONI, L. CAPELLI*, S. SIRONI}

4 Politecnico di Milano, Department of Chemistry, Materials and Chemical Engineering "Giulio

$5 \quad$ Natta" - Piazza L. da Vinci 32, 20133 Milano, Italy

$6 \quad *$ laura.capelli@polimi.it

7 ABSTRACT: The study addresses the problem of the assessment of odour emissions from 8 landfills. The aim of the project is the research concerning how to quantify odour emissions from

9 landfill surfaces, since there is no evidence of a widely accepted method to evaluate odour 10 emissions from this particular kind of source. Seven different methods have been developed and 11 investigated; these methods can be seen as based on three distinct approaches to the problem, 12 both experimental and computational. The first approach provides to use models for the estimation the landfill gas production, whereby the second and the third approach are based on

14 direct measurement campaigns on the landfill surface, for the determination either of the 15 methane or for the direct measurement of the odour concentration. The methods have then been 16 compared in terms of resulting odour impact by application of a specific atmospheric dispersion 17 model.

18 Keywords: odour impact assessment; dispersion modelling; surface sampling; wind tunnel; 19 satatic hood; flux chamber ${ }^{1}$.

LFG: landfill gas

OER: Odour Emission Rate

SOER: Specific Odour Emission Rate 


\section{INTRODUCTION}

21 Olfactory pollution is the immission of polluting compounds in the atmosphere that, although if not directly dangerous for the human health, are nonetheless characterized by intense and/or unpleasant smell. Typical examples are gaseous emissions coming from landfill surfaces (Ying et al., 2012), intensive farming, etc. This kind of pollution is one of the most significant causes of environmental discomfort since it lowers the quality of the environment and it may lead to psychophysiological disorders and a general worsened life quality (Palmiotto et al., 2014). In Italy there are no comprehensive regulations concerning the problem of odoriferous emissions. In order to devise proper strategies to reduce the nuisance related to odour emissions it is necessary to have specific methods for univocal odour assessment (Balling et al., 1980; Hobson, 1995; Stordeur, 1981), debunking the common belief that odour characterization is more art than

31 science (Koe, 1989; Jiang, 1996). While in the scientific community there is a satisfactory agreement regarding the analytical techniques - i.e. dynamic olfactometry for the determination of odour concentration (Sironi et al., 2014) - odour sampling is a quite more debated task, especially if diffused emissions or area sources are concerned. The evaluation of odour emissions from landfills is even more complicated, due to the specific characteristics of this kind of source, which is surely not an active area source, but neither properly a passive area source, as the landfill surface is typically crossed by a - low - flux, and there is currently no widely accepted method for odour assessment on landfills. However, landfills have always been considered as important sources of unpleasant odours, for this reason the development of specific methods for the assessment of odours emissions or the definition of specific odour emission factors would be

41 of great interest both for environmental authorities, as well as for landfill managers and operators. This is the reason why, in the present work, different methods for the evaluation of odour emissions from landfills have been inspected: the 7 methods developed are all retraceable to one 
of three distinct approaches to the matter.

The first approach - that comprises methods 1 and 2 - entails the usage of specific software for the quantification of the landfill gas (LFG) production: the software used in the first method is the US-EPA LandGEM, while the second method exploited a similar software specifically developed for the present project with some improved features with respect to the US-EPA LandGEM.

The second approach - that includes the third method - relies on the direct measurement of $\mathrm{CH}_{4}$ on the landfill surface, which involved the necessity to define a sampling methodology tailored for this peculiar type of source.

The third approach - that comprises methods 4, 5,6 and 7 - involves the direct measurement of the odour concentration at the source. In the fourth method the concentration was considered independent from the wind speed, while in methods $5,6,7$ the landfill surface was treated as a liquid area source, thereby considering the concentration as a function of the wind speed on the surface (Sironi et al., 2005).

Since the first two approaches evaluated are based on the quantification of methane emissions, the Odour Emission Rate (OER) needs to be obtained indirectly by multiplying the emitted gas flow rate by the LFG odour concentration. The odour concentration $\left(c_{o d}\right)$ of the LFG emitted through the landfill surface was estimeated by means of a correlation investigated between $c_{o d}$ and $c_{C_{4}}$.

The OER values obtained with the seven descripted methods were then used as inputs to run the atmospheric dispersion model CALPUFF, which allowed to visualize the odour impacts of the studied landfill resulting from the different emission scenarios considered. The impacts have then been compared with one another in order to make some consideration about the different models' accuracy and reliability. 


\section{MATERIALS AND METHODS}

70

71

\subsection{The Studied Site}

The chosen landfill is located in Northern Italy, and it is classified as "Landfill for NonHazardous Municipal Solid Waste Disposal”.

The site was chosen because it is object of repeated olfactometric monitoring campaigns by the Olfactometric Laboratory of Politecnico di Milano since several years: this allows to have access to a great amount of emission, olfactometric and meteorological data, as well as a consolidated experience about the landfill odour impact gained throughout the years, both crucial aspects for the present work. The landfill is operational since the early 1990s and has a waste processing capacity of several millions cubic meters, making it one of the biggest landfills in Northern Italy.

The site is subdivided in six allotments: now only one allotment is still active, all the others are closed.

In order to be able to apply the dispersion model to the emissions coming from a landfill, the whole area (about $250{ }^{\prime} 000 \mathrm{~m}^{2}$ ) needs to be considered as an emission source. For modelling purposes the landfill surface was divided in a reasonable number of emissive cells having smaller dimensions: 40 emissive cells were considered, a number of sources that is in line also with the suggestions of the User's Manual of the CALPUFF software (Scire et al., 2000). The geometry of the cells was kept as simple as possible (simple shapes like squares and triangles).

In order to glean the emission scenarios relying on an experimental approach it was also necessary to carry out tailored campaigns in the field. The campaigns spanned from 1/3/2014 to $30 / 10 / 2014$ and interested mainly allotment 1 , which is the oldest one.

The software initially used to assess the methane production is the US-EPA LandGEM (Alexander et al., 2005); hereafter another newer software was adopted, similar to the default LandGEM but with some reasoned modifications. This will be discussed in the following sections. 


\subsection{Modifications To The LandGEM Software}

One of the novel aspects of the present study regarded the modification and improvement of the US-EPA LandGEM software aiming to optimize its performances. The main improvement concerns the input mode of the initial parameters of the model which the software is very sensitive to. More in detail, the biggest flaw in the default model is in the input procedure of the fundamental parameters of the model, since besides the waste inflow that can be considered changing year by year, the other parameters, i.e. the methane generation rate $(k)$ and the methane generation potential $\left(L_{0}\right)$, are kept constant for the whole simulation (Alexander et al., 2005). This aspect makes it impossible to account for the possible variations that may occur as a consequence of a change in the processed MSW quality, given that both $(k)$ and $\left(L_{0}\right)$ show a strong dependence on the bio-degradability of the considered waste.

The many regulations addressing the problem of landfill management have defined the "classes" of wastes treated there and this classification has been known to change over time. In the end it is the class of the waste that affects the most the two input parameters $(k)$ and $\left(L_{0}\right)$ : at this point it is evident that assuming them unchangeable is an unacceptable approximation. Thus, the innovative idea is the possibility of considering these two key parameters as well varying year by year. The modified software maintains the same Graphical User Interface (GUI) in MS Excel as the standard US-EPA LandGEM and allows to consider the parameters $(k)$ and $\left(L_{0}\right)$ changing yearly.

\subsection{Design And Development Of Specific Sampling Procedures}

It is necessary to clarify the particular nature of the landfill source typology. This kind of source is an area source but it cannot be defined neither active nor passive, referring to the classification made in the german guideline VDI 3880 (VDI, 2011). In fact, even if not presenting a significant outflow - typical of the active sources - it has a distinct non-zero emission flow that cannot be 
118 neglected. This is why it is necessary to develop specific sampling devices and procedures for 119 this unique type of source.

120 The first method adopted for the direct measure of methane emissions on the considered landfill 121 surface was the so-called Static Hood device $(\mathrm{SH})$ that was specifically realized starting from a 122 design found in the scientific literature that was deemed appropriate (Rachor et al., 2013). The 123 mentioned work was picked as reference since it is a rare example of a study that involved tests 124 and experiments in the field that were repeatable and that were performed over a rather long 125 period (i.e. 2 years). The hood geometry proposed in that research paper is cylindrical, $50 \mathrm{~cm}$ 126 high with a base section of $0.12 \mathrm{~m}^{2}$. Within the research group further considerations were 127 pondered concerning the geometry of the hood. In particular, about the height of the chamber two 128 considerations were made, concerning on one hand molecular diffusion, the most significant 129 phenomenon in the process, and on the other hand the $\mathrm{CH}_{4}$ ascension velocity, which depends on 130 the LFG outflow from the landfill surface, and was hypothesized as monodimensional 131 (perpendicular to the surface).

132 Since both processes are rather slow, it was concluded that it was necessary to have a shorter 133 hood, minimizing its height in order to have a homogeneous methane concentration profile in the 134 hood. The chamber assembled at Politecnico is $10 \mathrm{~cm}$ high, allowing both an easy placement of 135 the hood on the surface and an accurate measure; the base section is $0.25 \mathrm{~m}^{2}$ and the material 136 used is steel, providing the required robustness to withstand the stresses involved in the laying of 137 the device. The chamber is provided with lateral flanges to avoid excessive plunging in the soil. 138 The hood is equipped with an open tube that connects the interior to the exterior of the hood, in 139 order to keep the internal pressure equal to the external pressure, thus avoiding overpressures that 140 may affect the LFG emission from the surface portion covered by the hood.

141 The emitted methane flow can be evaluated according to the following mass balance:

$$
Q_{C_{4}}=\frac{V_{\text {hood }}}{S_{\text {hood }}} * \frac{\partial c_{C H_{4}}}{\partial t}
$$


143 Once the $\mathrm{CH}_{4}$ flow rate is known, it is possible to calculate the LFG emission by considering the

144 LFG composition (i.e., the $\mathrm{CH}_{4}$ content). A specific procedure for sampling was designed,

145 providing that after each measurement the hood is lifted and ventilated, in order to minimize

146 LFG build-up in the hood and perturbations on the emission source. Afterwards, the hood is

147 positioned on the same spot and the next measure is performed, restarting the time count from

148 time zero.

149 After the found experimental correlation was proved to agree with the theoretical expectations, 150 the sampling time for measurements with the static hood was defined in 10 minutes. The hood 151 developed is portrayed in Fig.1.

Figure 1

154 Another device was involved in the study, a Flux Chamber (FC) similar to the one designed by 155 the US EPA (Klenbusch, 1986) to be used in fluxed experiments. The hood realized at 156 Politecnico is hemispherical with a $50 \mathrm{~cm}$ diameter and a $32 \mathrm{dm}^{3}$ volume. The emitted methane

157 flow in this case can be calculated as shown in Eq. 2 where the fluxes are expressed in $\mathrm{dm}^{3} / \mathrm{h}$ :

$$
F_{\text {air }}+F_{\mathrm{CH}_{4}}=F_{\text {out }}
$$

159 This sampling procedure is the one used for collecting samples to be analysed by means of

160 olfactometry. The main reason behind is that odour samples have typical volumes of $6 \mathrm{dm}^{3}$ and 161 considering a static hood with a volume of $25 \mathrm{dm}^{3}$ this would mean a huge perturbation of the 162 system that would affect the results; the inconvenience can be overcome operating with a Flux 163 Chamber where the volume inside the hood is constantly recirculated thanks to the continuous air

164 flow. Also in this case different tests were performed: several experiments were conducted 165 adopting an air flow rate ranging between $100 \mathrm{dm}^{3} / \mathrm{h}$ and $300 \mathrm{dm}^{3} / \mathrm{h}$, thereby verifying that the measured concentration is inversely proportional to the flow rate. Then, a specific sampling 
167 procedure for the measurement of both $\left(c_{o d}\right)$ and $\left(c_{C H_{4}}\right)$ with the Flux Chamber was defined.

168 The neutral air flow rate was defined in $200 \mathrm{dm}^{3} / \mathrm{h}$ while the sampling time in 12 minutes. The 169 Flux Chamber is depicted in Fig.2:

172 Another device that was used in the present work was the Wind Tunnel (WT), which was 173 designed at Politecnico in a previous project for odour sampling from passive area source 174 (Capelli et al., 2009), with the aim of making the flow fluxed in the hood as uniform as possible, 175 in order to realistically simulate the action of the wind on the surface (Jiang et al., 1995). Even if 176 this sampling system was validated and codified only for liquid area sources - while the studies 177 to validate it also for solid area sources are still ongoing (Capelli et al., 2012) - it was decided to 178 use it for the determination of the odour emissions from the landfill surface since it represents the 179 only sampling system available that has been validated for passive area sources. However, it is 180 known that for area sources characterized by a very low emissivity, it tends to overestimate the 181 actual emission (Frechen et al., 2004; VDI, 2011). Previous studies on the Wind Tunnel led to 182 the definition of the optimal sweep air flow rate, found to be $2500 \mathrm{dm}^{3} / \mathrm{h}$ (Capelli et al., 2009). At 183 the outlet of the Wind Tunnel an odour sample is collected in a specific Nalophan ${ }^{\mathrm{TM}}$ bag by 184 means of a vacuum pump. From the odour concentration it is possible to evaluate the Specific 185 Odour Emission Rate (SOER) expressed in $\left[\mathrm{ou}_{\mathrm{E}} / \mathrm{s} / \mathrm{m}^{2}\right]$ according to Eq.3:

$$
S O E R=\frac{c_{O d^{*} Q_{a i r}}}{A_{W T}}
$$

With: $\quad \mathrm{c}_{o d}=$ odour concentration $\left[\mathrm{ou}_{\mathrm{E}} / \mathrm{m}^{3}\right]$ 
The OER is then obtained by multiplying the SOER by the site surface. The outlet odour

192 concentration, the SOER and the OER, i.e. the amount of odorous compounds that migrate to the gas phase as a consequence of forced convection, are a function of the defined sweep flow rate. More in detail, considering the motion regime laminar, assuming that the mass transfer

195 phenomena can be described by the laws of Prandtl's Fluid-Dynamic Boundary Layer Theory, it

196 is possible to deduce that both SOER and OER will be proportional to the square root of the sweep air velocity as shown in Eq.4, where $\alpha$ is a proportionality constant and the hypothesis of laminar motion regime holds true:

$$
\text { SOER,OER }=\alpha v^{\frac{1}{2}}
$$

This means that the OER data obtained with the WT will need to be recalculated at the correct wind speed for each hour of the simulation time domain, before using them as inputs for the CALPUFF dispersion model (Jiang et al., 2001; Sohn et al., 2003); this operation can be done according to Eq.5:

$$
O E R_{v_{2}}=O E R_{v_{1}}\left(\frac{v_{2}}{v_{1}}\right)^{\frac{1}{2}}
$$

In Eq.5 $v_{1}$ is the air speed during the sampling conditions - in our case corresponding to 0.035 $\mathrm{m} / \mathrm{s}-$ while $v_{2}$ is the wind speed at a specific hour of the time domain of the simulation.

\subsection{Evaluation Of The Emitted LFG Odour Concentration}

In order to be able to assess the odour emissions associated with the LFG emissions from the

209 landfill surface, it is necessary to know the effluent flow rate and its odour concentration, 210 required for OER calculation. The determination of the odour concentration of the LFG emitted 211 from the landfill surface is a quite complicated task: in literature there are some odour 212 concentration values relevant to pure LFG (Sironi et al., 2005), but these values overestimate the 213 concentration of the LFG emitted through the landfill surface, as they do not consider the effects 214 of odour concentration reduction that occur while the gas crosses the landfill surface cover 
215 material (Capanema et al., 2014). For this reason, it was decided to try to estimate the LFG odour

216 concentration by investigating the correlation between the $\mathrm{CH}_{4}$ concentration (in ppm) and the

217 odour concentration (in $\mathrm{ou}_{\mathrm{E}} / \mathrm{m}^{3}$ ). For this purpose, specific sampling campaigns at the landfill

218 were conducted, where the sampling method involved the Flux Chamber both for the assessment

219 of $\mathrm{CH}_{4}$ concentration and for the retrieval of odour samples for olfactometric analysis. The

220 resulting values underwent a screening process: in particular the odour concentration values

221 below $40 \mathrm{ou}_{\mathrm{E}} / \mathrm{m}^{3}$ were neglected due to the detection limits that are characteristic of the 222 olfactometric analysis. The remaining data were then plotted with methane concentration on the 223 axis of abscissae and the odour concentration on the axis of ordinates.

224 The resulting correlation is here reported:

$$
y=0.6907 x+83.026
$$

In Eq.6 (x) is $\left(c_{\mathrm{CH}_{4}}\right)$ in ppm while $(\mathrm{y})$ is $\left(c_{O d}\right)$ in $\mathrm{ou}_{\mathrm{E}} / \mathrm{m}^{3}$. Since in this case the $\mathrm{CH}_{4}$ concentration in LFG is assumed to be $50 \%$, i.e. $500000 \mathrm{ppm}$, the resulting odour concentration for the LFG turned out to be $345000 \mathrm{ou}_{\mathrm{E}} / \mathrm{m}^{3}$.

\subsection{Optimization Of The Model For The Assessment Of The Wind Speed Depending}

\section{Emission Rate}

231 When it is necessary to recalculate OER as a function of the wind speed, it is necessary to define 232 which wind speed has to be considered. In this sense, it was decided to investigate what 233 differences were observed when using the wind speed recalculated at source level (at $2 \mathrm{~m}$ ) 234 instead of the one recorded by the meteorological station (at $10 \mathrm{~m}$ ). Two possible laws were 235 considered for wind speed recalculation: a Power Law and a Logarithmic Law. The resulting 236 models and impacts were then compared with one another:

- $\quad$ in the first case the OER recalculation considered the wind speed recorded at $10 \mathrm{~m}$; 
with a Power Law model that is obtained empirically starting from a known velocity at certain height, the height corresponding to the desired wind velocity and a so-called Hellman's parameter that depends on terrain and stability class. This can be viewed formulaically in Eq.7. The model is suggested in the heights range 30-300 m (Cook, 1997);

$$
v_{w}^{h 1}=v_{w}^{h 2} *\left(\frac{h 1}{h 2}\right)^{\alpha}
$$
2013; Tieleman, 2008):

$$
v_{w}^{h}=\frac{u_{*}}{k}\left[\ln \left(\frac{h}{z}\right)+5.75\left(\frac{h}{H}\right)-1.88\left(\frac{h}{H}\right)^{2}-1.33\left(\frac{h}{H}\right)^{3}+0.25\left(\frac{h}{H}\right)^{4}\right]
$$

\section{RESULTS AND DISCUSSION}

\subsection{Determination Of The Emitted LFG Flow Rate With LandGEM, normal and modified}

It is necessary to underline that the LandGEM provides the LFG production rate, not the LFG 
261 parameters for the US EPA software. According to the regulations in force since 1993 and until 262 2013, the value of the production rate $(\mathrm{k})$ during the landfill operation years was determined. 263 Then the arithmetical mean of these values was picked as the value to be used in the simulations 264 involving the standard US EPA software. The obtained value is reported in Eq.10:

$$
k=0.038 y^{-1}
$$

266 Analogously, also for the biogas generation potential $\left(\mathrm{L}_{0}\right)$ the mean value was used for running 267 the program; the resulting value is shown in Eq.11:

$$
L_{0}=135 \mathrm{~m}^{3} / \mathrm{Mg}
$$

The $\mathrm{CH}_{4}$ concentration in the LFG was considered equal to 500 '000 ppm, which is the average value relvant to the site under investigation. It is possible to run the LandGEM software and obtain the flow rate of the $\mathrm{CH}_{4}$ produced by the landfill for the year 2014, reported in Eq.12:

$$
Q_{L F G}=3.545 * 10^{7} \mathrm{~m}^{3} / y
$$

Then, knowing the LFG flow rate collected by the collection system, which in the studied case is equal to $2200 \mathrm{~m}^{3} / \mathrm{h}$, the LFG emission can be then evaluated as shown in Eq.13:

$$
Q_{\text {emitted }}=Q_{\text {tot }}-Q_{\text {collect }}=1872.77 \mathrm{~m}^{3} / \mathrm{h}
$$

276 The landfill OER is then calculated considering the LFG odour concentration, which was considered equal to $345^{\prime} 000 \mathrm{ou}_{\mathrm{E}} / \mathrm{m}^{3}$ (Eq. 6) as shown in Eq.14:

$$
O E R=Q_{\text {emitted }} * c_{o d}=179473 \text { ou }_{E} / s
$$

279 It is also possible to obtain the SOER of the landfill, by dividing the OER by the surface of the 280 site as expressed in Eq.15:

$$
S O E R=\frac{O E R}{A_{\text {tot }}}=0.88 \quad o u_{E} /\left(s * m^{2}\right)
$$

282 From Eq.15 it is possible to determine the OER for each emissive cell, multiplying the SOER by 283 each cell surface. The outcome is the input for the CALPUFF dispersion model. The obtained 
emission data are used as input for the CALPUFF atmospheric dispersion model, producing the impact depicted in Fig.3.

The odour impact in Fig.3 is represented on a $4 \mathrm{~km}$ by $4 \mathrm{~km}$ map centred on the landfill, the shown iso-concentration lines represent the $98^{\circ}$ percentile of the hourly averaged odour concentrations considering a peak-to-mean ratio of 2.3 ; this means that the mean values are multiplied by a factor that accounts for peak oscillations around the mean value of concentration over 60 minutes (Schauberger et al., 2012). The isopleths represented in the impact map refer to the range of concentration between 1 and $10 \mathrm{ou}_{\mathrm{E}} / \mathrm{m}^{3}$.

These parameters are a commonly accepted choice and are those suggested by the guidelines issued by Regione Lombardia (D.g.r. n. IX/3018, 2012), which is the only regulation addressing the problem of olfactory pollution available in Italy. Looking at Fig.3 it is possible to observe a significant impact since the isopleths cover almost the entire map. This result is likely to be an over-estimation of the real impact since the many years of odour monitoring campaigns conducted by the Olfactometric Laboratory of Politecnico at this exact site never highlighted a critical situation such as the one depicted in Fig.3.

Regarding the application of the modified LandGEM, considering the average rainfall of the site 300 and the influence that the nature of the waste has on the LandGEM parameters $(\mathrm{k})$ and $\left(\mathrm{L}_{0}\right)$, their values were defined for each year of landfill operation. The biogas amount produced in 2014, computed with the modified software is reported in Eq.16:

$$
Q_{\text {tot }}=3.427 * 10^{7} \mathrm{~m}^{3} / y
$$

304 Then it was possible to evaluate the actually emitted flow rate considering the same collected 305 flow of $2200 \mathrm{~m}^{3} / \mathrm{h}$. Then the OER and SOER can be assessed as in the previous case. The calculations are shown in Eq.17, Eq.18 and Eq.19:

$$
\begin{gathered}
Q_{\text {emitted }}=Q_{\text {tot }}-Q_{\text {collect }}=1712.58 \mathrm{~m}^{3} / \mathrm{h} \\
O E R=Q_{\text {emitted }} * C_{o d}=164122 \mathrm{ou}_{E} / \mathrm{s}
\end{gathered}
$$




$$
S O E R=\frac{O E R}{A_{\text {tot }}}=0.80 \mathrm{ou}_{E} /\left(s * \mathrm{~m}^{2}\right)
$$

311 From Eq.19 it is possible to determine the OER for each emissive cell, multiplying the SOER by 312 each cell surface. The outcome is the input for the CALPUFF dispersion model (Fig. 3, right).

313

Figure 3.

In Fig. 3 it is possible to see the impact resulting from this method. Even if the OER is reduced with respect to the first method, the impact shown in Fig.6 is still overestimated. The new model with modified LandGEM shows an improvement since the impact over-estimation is reduced; but the main criticity relevant to this approach is that both models produce an esteem of the LFG production, not the emission and this is conceptually a step back with respect to the characterization of the LFG emissions from landfill surfaces.

\subsection{Experimental Measure Of The $\mathrm{CH}_{4}$ Concentration On The Landfill Surface}

The results here presented refer to $\mathrm{CH}_{4}$ concentration measures conducted in the field in the year 2014 adopting a sampling methodology that involved the use of a Flux Chamber with a neutral air flow rate of $200 \mathrm{dm}^{3} / \mathrm{h}$. After evaluating the mean of all measured values, which turned out to be equal to $47 \mathrm{ppm}$, it was possible to determine the LFG flow rate by means of a mass balance written for the Flux Chamber. Assuming as usual that the methane concentration in the pure biogas is $50 \% \mathrm{v} / \mathrm{v}$, it is possible to compute the emitted biogas flow rate as shown in Eq.20:

$$
Q_{L F G}=\frac{Q_{C H_{4}}}{c_{C H_{4}}^{\text {theoure }}}=0.003 \frac{\mathrm{m}^{3}}{\mathrm{~s}}
$$

Using the correlation of Eq.6 the odour concentration of the biogas can be evaluated - equal to $345^{\prime} 000 \mathrm{ou}_{\mathrm{E}} / \mathrm{m}^{3}$ - and consequently also the OER, as shown in Eq.21: 


$$
O E R_{\text {landfill }}=c_{o d} * Q_{L F G}=1023.5 \frac{o u_{E}}{s}
$$

332 The SOER is then calculated according to Eq.22, from which it is possible to determine the OER 333 for each emissive cell. The outcome is the input for the CALPUFF dispersion model which 334 provides the impact depicted in Fig.4 (left).

$$
S O E R_{\text {landfill }}=\frac{O E R_{\text {landfill }}}{A_{\text {tot }}}=0.005 \frac{o u_{E}}{s * m^{2}}
$$

Just looking at the OER and SOER values obtained with this method it is possible to foresee that the resulting impact will be much less significant than in the previous cases, and looking at Fig.4 makes it visually evident. It is important to highlight that in all impact maps the concentration range represented is $1-10 \mathrm{ou}_{\mathrm{E}} / \mathrm{m}^{3}$, but in this particular case since the maximum value is lower than $1 \mathrm{ou}_{\mathrm{E}} / \mathrm{m}^{3}$, the selected range is $0.1-1 \mathrm{ou}_{\mathrm{E}} / \mathrm{m}^{3}$. A very low emission such as the one obtained in this scenario can be explained since the sampling campaigns have been conducted only on allotment 1 , the oldest one that is closed since 1994 and this probably led to an under-estimation of the real impact of the landfill, which is still operational.

Figure 4.

\subsection{Experimental Measure Of The Odour Concentration On The Landfill Surface}

347 Adopting the same sampling methodology used in method 3 (Flux Chamber), in this case 11 air 348 samples were collected from the site that underwent an olfactometric analysis in order to 349 determine their odour concentration. The geometric mean of the odour concentrations was 350 calculated and turned out to be $135 \mathrm{ou}_{\mathrm{E}} / \mathrm{m}^{3}$. The SOER was obtained as shown in Eq.23:

$$
S O E R=\frac{c_{o d}\left[\frac{o u_{E}}{m^{3}}\right] * Q_{\text {air }}\left[\frac{m^{3}}{s}\right]}{A_{\text {hood }}\left[m^{2}\right]}=\frac{135 * 200}{1000 * 3600 * 0.25}=0.03 \frac{o u_{E}}{m^{2} s}
$$

352 Also in this situation both the OER and the resulting odour impact are very low, as can be seen in 
353 Fig.4 (right). Methods 3 and 4 produce relatively coherent results, thus confirming the hypothesis 354 of a correlation existing between odour concentration and $\mathrm{CH}_{4}$ concentration. Even if both 355 methods under-estimate the real emissions, because relying on data gathered only from allotment 3561 , the approaches involving experimental campaigns in the field with the Flux Chamber seem to 357 be the most reliable tools for the assessment of odour emissions from landfill surfaces.

\subsection{Assessment Of The OER As A Function Of The Wind Speed}

In this scenario the landfill is assumed as a completely passive area source; thus conducing sampling by means of a Wind Tunnel. In this case 15 samples were collected and analysed, giving an average odour concentration of $218 \mathrm{ou}_{\mathrm{E}} / \mathrm{m}^{3}$. Then the SOER was evaluated according to Eq.24:

$$
S O E R=\frac{c_{o d^{*}} Q_{a i r}}{A_{W T}}=1.21 \frac{o u_{E}}{m^{2} s}
$$

In this case, the OER obtained needs to be pre-processed before being used in the dispersion model; it is necessary to recalculate it as a function of the actual wind velocity at each hour of the simulation time domain according to Eq.5.

In method 5 the wind speed $v_{2}$ is the velocity recorded at a meteorological station nearby, at a height of $10 \mathrm{~m}$. The velocity $\mathrm{v}_{1}$ is the velocity inside the Wind Tunnel, i.e. $3.5 \mathrm{~cm} / \mathrm{s}$. The obtained OER values are used as input of the dispersion model producing the impact shown in Fig.5 (left). It is possible to observe that the isopleths cover the whole area of the map. The odour impact is very high and, as discussed for methods 1 and 2, it is an overestimation with respect to the real situation. In the last two scenarios - methods 6 and 7 - as previously mentioned, the wind speed used for the OER recalculation is the one evaluated at the source level, i.e. $2 \mathrm{~m}$, with tailored wind profile models exploiting a Power Law and a Logarithmic Law, respectively. The resulting odour impacts obtained with the dispersion model CALPUFF can be observed in Fig.5 (centre and 
right).

Figure 5.

379 It is worth underlying that methods 5, 6, 7 all share a common flaw, given by the fact that they

380 consider the landfill surface as a passive area source, and therefore the emissions as a function of 381 the wind speed over the emitting surface. It is likely that the LFG emissions from landfill 382 surfaces have a dependence on the meteorological parameters that may affect the phenomenon, 383 but the assumption that there is a well-defined dependence on the wind speed - which is true for 384 passive area sources - for this source typology, is groundless since in this case the driving 385 phenomenon of the whole process is not forced convection.

\subsection{Comparison Of The OER Obtained With The Different Methods}

In order to compare the different approaches adopted, Tab.1 summarizes the OER values obtained with methods 2,4 and 7 . These three were picked since - among the proposed approaches - they look like the best LandGEM-based method, the best Flux-Chamber-based method and the best Wind-Tunnel-based method respectively. More in detail, Tab.1 highlights how the OER order of magnitude changes from one method to the next one. Relying on a careful consideration and on the direct experience, it is believed that the most reliable methods are methods 3 and 4: they are experimental methods involving direct measurement campaigns in the

394 field with a tailored sampling system adopting a specifically designed Flux Chamber device.

\section{CONCLUSIONS}

The purpose of the present work was the investigation of specific methods for the quantification

397 of odour emissions from landfill surfaces since up to date there are no codified and universally

398 accepted methodologies to address this peculiar problem. In facts, landfills represent a particular 
399 type of area sources that cannot be considered nor fully active nor fully passive.

400 Table 1. Estimated OER comparison for methods 2, 4 and 7.

\begin{tabular}{|c|c|c|c|c|c|}
\hline Cell Name & $\begin{array}{l}\text { Cell UTM East } \\
\text { Coordinates [m] }\end{array}$ & $\begin{array}{l}\text { Cell UTM North } \\
\text { Coordinates [m] }\end{array}$ & $\begin{array}{c}\text { OER Mod. } 2 \\
{\left[\mathrm{ou}_{\mathrm{E}} / \mathrm{s}\right]}\end{array}$ & $\begin{array}{c}\text { OER Mod. } 4 \\
{\left[\mathrm{ou}_{\mathrm{E}} / \mathrm{s}\right]}\end{array}$ & $\begin{array}{c}\text { OER Mod. } 7 \\
{\left[\mathrm{ou}_{\mathrm{E}} / \mathrm{s}\right]}\end{array}$ \\
\hline $\mathrm{A} 01$ & $493808 \mathrm{E}$ & $5056844 \mathrm{~N}$ & 5156.4 & 192 & 14532.3 \\
\hline $\mathrm{A} 02$ & $493881 \mathrm{E}$ & $5056871 \mathrm{~N}$ & 5156.4 & 192 & 14532.3 \\
\hline $\mathrm{A} 03$ & $493953 \mathrm{E}$ & $5056899 \mathrm{~N}$ & 5156.4 & 192 & 14532.3 \\
\hline $\mathrm{A} 04$ & $494029 \mathrm{E}$ & $5056930 \mathrm{~N}$ & 5156.4 & 192 & 14532.3 \\
\hline A05 & $494095 \mathrm{E}$ & $5056955 \mathrm{~N}$ & 5156.4 & 192 & 14532.3 \\
\hline A06 & $493774 \mathrm{E}$ & $5056904 \mathrm{~N}$ & 5156.4 & 192 & 14532.3 \\
\hline $\mathrm{A} 07$ & $493845 \mathrm{E}$ & $5056932 \mathrm{~N}$ & 5156.4 & 192 & 14532.3 \\
\hline A08 & $493917 \mathrm{E}$ & $5056962 \mathrm{~N}$ & 5156.4 & 192 & 14532.3 \\
\hline A09 & $493993 \mathrm{E}$ & $5056991 \mathrm{~N}$ & 5156.4 & 192 & 14532.3 \\
\hline A10 & $494060 \mathrm{E}$ & $5057016 \mathrm{~N}$ & 5156.4 & 192 & 14532.3 \\
\hline A11 & $493733 \mathrm{E}$ & $5056973 \mathrm{~N}$ & 5156.4 & 192 & 14532.3 \\
\hline A12 & $493805 \mathrm{E}$ & $5057001 \mathrm{~N}$ & 5156.4 & 192 & 14532.3 \\
\hline A13 & $493877 \mathrm{E}$ & $5057029 \mathrm{~N}$ & 5156.4 & 192 & 14532.3 \\
\hline A14 & $493552 \mathrm{E}$ & $5057059 \mathrm{~N}$ & 5156.4 & 192 & 14532.3 \\
\hline A15 & $494016 \mathrm{E}$ & $5057092 \mathrm{~N}$ & 5156.4 & 192 & 14532.3 \\
\hline A16 & $493692 \mathrm{E}$ & $5057041 \mathrm{~N}$ & 5156.4 & 192 & 14532.3 \\
\hline A17 & $493764 \mathrm{E}$ & $5057069 \mathrm{~N}$ & 5156.4 & 192 & 14532.3 \\
\hline A18 & $493837 \mathrm{E}$ & $5057097 \mathrm{~N}$ & 5156.4 & 192 & 14532.3 \\
\hline A19 & $493911 \mathrm{E}$ & $5057128 \mathrm{~N}$ & 5156.4 & 192 & 14532.3 \\
\hline A20 & $493650 \mathrm{E}$ & $5057109 \mathrm{~N}$ & 5156.4 & 192 & 14532.3 \\
\hline B01 & $493724 \mathrm{E}$ & $5057138 \mathrm{~N}$ & 2922.2 & 108.8 & 8235.7 \\
\hline $\mathrm{C01}$ & $493796 \mathrm{E}$ & $5057166 \mathrm{~N}$ & 3931.7 & 146.4 & 11080.9 \\
\hline D01 & $493870 \mathrm{E}$ & $5057196 \mathrm{~N}$ & 4816.4 & 179.3 & 13574.1 \\
\hline E01 & $493921 \mathrm{E}$ & $5057225 \mathrm{~N}$ & 3113.2 & 115.9 & 8773.9 \\
\hline F01 & $493609 \mathrm{E}$ & $5057177 \mathrm{~N}$ & 1728.2 & 64.4 & 4870.6 \\
\hline G01 & $493682 \mathrm{E}$ & $5057206 \mathrm{~N}$ & 4146 & 154.4 & 11684.9 \\
\hline $\mathrm{HO1}$ & $493756 \mathrm{E}$ & $5057236 \mathrm{~N}$ & 4146 & 154.4 & 11684.9 \\
\hline 101 & $493830 \mathrm{E}$ & $5057266 \mathrm{~N}$ & 4413.5 & 164.3 & 12438.8 \\
\hline $\mathrm{J} 01$ & $493538 E$ & $5057150 \mathrm{~N}$ & 3741.6 & 139.3 & 10545 \\
\hline K01 & $493558 \mathrm{E}$ & $5057108 \mathrm{~N}$ & 1423.6 & 53 & 4012.3 \\
\hline L01 & $493590 \mathrm{E}$ & $5057055 \mathrm{~N}$ & 3029.4 & 112.8 & 8537.8 \\
\hline M01 & $493622 \mathrm{E}$ & $5057001 \mathrm{~N}$ & 1482.5 & 55.2 & 4178.1 \\
\hline N01 & $493964 \mathrm{E}$ & $5057166 \mathrm{~N}$ & 513.2 & 19.1 & 1446.4 \\
\hline 001 & $493674 \mathrm{E}$ & $5056935 \mathrm{~N}$ & 1031.3 & 38.4 & 2906.5 \\
\hline P01 & $493526 \mathrm{E}$ & $5057177 \mathrm{~N}$ & 1218.2 & 45.4 & 3433.3 \\
\hline Q01 & $493644 \mathrm{E}$ & $5057246 \mathrm{~N}$ & 4060.6 & 151.2 & 11444.2 \\
\hline $\mathrm{Q} 02$ & $493715 \mathrm{E}$ & $5056895 \mathrm{~N}$ & 4060.6 & 151.2 & 11444.2 \\
\hline
\end{tabular}




\begin{tabular}{|l|l|l|l|l|l|}
\hline $\mathrm{Q} 03$ & $493529 \mathrm{E}$ & $5057202 \mathrm{~N}$ & 4060.6 & 151.2 & 11444.2 \\
\hline $\mathrm{Q} 04$ & $493748 \mathrm{E}$ & $5057281 \mathrm{~N}$ & 4060.6 & 151.2 & 11444.2 \\
\hline $\mathrm{R} 01$ & $493881 \mathrm{E}$ & $5057279 \mathrm{~N}$ & 3096.2 & 115.3 & 8726.2 \\
\hline
\end{tabular}

402 Different methods for the evaluation of odour emissions from landfill surfaces were developed and investigated. At first the LandGEM-based method was considered and a new possibility was explored modifying the default US-EPA software. The improved software designed allows to consider the two most significant input parameters of the LandGEM model variable yearly according to a set of aspects such as waste quality and composition. The new software shows an improvement with respect to the standard version of LandGEM, reducing the over-estimation by $10 \%$. This improvement does not fix the underlying flaws of the concept of using a model for the estimation of the LFG generation for environmental emission assessment purposes (Capelli et al., 2014).

411 Another novel feature of the research is the optimization of the OER recalculation procedure 412 involved in the methods relying on measurements with the Wind Tunnel. The changes also in 413 this case led to an improvement of the previous situation but ultimately proved that anyhow the 414 application of the Wind Tunnel to landfills, i.e. their assimilation to passive area sources, even 415 though they characterized by a minimal yet non-negligible emissive flow which is not affected 416 by forced convection, leads to an over-estimation of the OER.

417 Another aspect of the work entailed the estimation of the odour concentration of the LFG emitted 418 through the landfill surface by means of specific olfactometric campaigns aiming to correlate 419 odour and $\mathrm{CH}_{4}$ concentration of the emitted LFG. The found correlation even though not 420 exceptional is satisfactory, but further studies will be required in order to increase data 421 robustness. In the future probably the samples should be collected not only in allotment 1 422 (closed), but in all allotments including the still active one.

423 Finally, the most significant result of the present work was the clear statement that experimental 424 campaigns on site are fundamental for these kind of evaluations. Moreover, two sampling 
systems, i.e. Static Hood and Flux Chamber, were designed and tested, and the optimal sampling 426 procedures were defined for the two devices; this led to the determination of a precise chain of 427 actions for both the Static Hood and the Flux Chamber measurements.

428 Actually, it is here necessary to stress that the proposed emission models will have to be further 429 compared and weighed by means of specific validation measurement campaigns in the field 430 involving for instance field inspections, questioning and/or electronic noses (Capelli et al., 2013). 431 Moreover, future investigations and experimental campaigns will need to span on larger temporal 432 scales in order to be able to highlight other aspects affecting emissions such as seasonal effects 433 and dependence on meteorological conditions.

\section{REFERENCES}

Alexander A., Burklin C., Singleton A., 2005. Landfill Gas Emissions Model (LandGEM) Version 3.02 User's Guide, US EPA-600/R-05/047, Washington DC.

Balling R.C., Reynolds C.E., 1980. A model for evaluating the dispersion of wastewater plant odors. Water Pollut. Control 52, 2589-2593.

Capanema M. A., Cabana H., Cabral A. R., 2014. Reduction of odours in pilot-scale landfill biocovers. Waste Manage. 34, 770-779. DOI 10.1016/j.wasman.2014.01.016.

Capelli L., Sironi S., Del Rosso R., Centola P., 2009. Design and validation of a Wind Tunnel system for odour sampling on liquid area sources. Water Sci. Technol. 59, 1611-1620. DOI 10.2166/wst.2009.123. 
449 Capelli L., Sironi S., Barczak R., Il Grande M., Del Rosso R., 2012. Validation of a method for 450 odor sampling on solid area sources. Water Sci. Technol. 66, 1607-1613. DOI $451 \quad 10.2166 /$ wst.2012.361.

453 Capelli L., Sironi S., Del Rosso R., Guillot J.-M., 2013. Measuring odours in the environment vs. 454 dispersion modelling: A review. Atmos. Environ. 79, 731-743. DOI 455 10.1016/j.atmosenv.2013.07.029.

457 Capelli L., Sironi S., Del Rosso R., Magnano E., 2014. Evaluation of landfill surface emissions. 458 Chem. Eng. Trans. 40, 187-192. DOI 0.3303/CET1440032.

460 Cook N.J., 1997. The Deaves and Harris ABL model applied to heterogeneous terrain. J. Wind 461 Eng. Ind. Aerod. 66, 197-214.

462

D.G.R. 15 febbraio 2012 e n. IX/3018 Regione Lombardia, 2012. Determinazioni generali in 464 merito alla caratterizzazione delle emissioni gassose in atmosfera derivanti da attività a forte 465 impatto odorigeno, pp. 20e49. Bollettino Ufficiale 20 febbraio 2012.

467 Drew D.R., Barlow J.F., Lane S.E., 2013. Observations of wind speed profiles over Greater 468 London, UK, using a Doppler lidar. J. Wind Eng. Ind. Aerod. 121, 98-105, DOI $469 \quad$ 10.1016/j.jweia.2013.07.019.

471 Frechen F.B., Frey M., Wett M., Löser C., 2004. Aerodynamic performance of a low-speed Wind 472 Tunnel. Water Sci. Technol. 50, 57-64. 
Hobson J., 1995. The odour potential: a new tool for odour management. Water Environ. J. 9, 458-463. DOI 10.1111/j.1747-6593.1995.tb01483.x.

Jiang J.K., Bliss P.J., Schulz T.J., 1995. The development of a sampling system for determining odor emission rates from area surfaces: Part I. aerodynamic performance. J. Air Waste Manage. 45, 917-922.

Jiang J.K., 1996. Concentration measurement by dynamic olfactometer. J. Water Environ. Tech. $8,55-58$.

Jiang J.K., Kaye R., 2001. Sampling techniques for odour measurement. Odours in Wastewater Treatment: Measurement, Modelling and Control, IWA Publishing, London.

Klenbusch M.R., 1986. Radian Corporation for the US EPA. Measurement of gaseous emission rates from land surfaces using an emission isolation flux chamber, US EPA, Las Vegas.

Koe L.C.C., 1989. Sewage odors quantification. Encyclopedia of Environmental Control Technology, Wastewater Treat. Technol. 3, cd P.N. Cheremisinoff, 423-446. Gulf Publishing Company, Houston.

4 Palmiotto M., Fattore E., Paiano V., Celeste G., Colombo A., Davoli E., 2014. Influence of a municipal solid waste landfill in the surrounding environment: Toxicological risk and odor nuisance effects. Environ. Int. 68, 16-24. DOI 10.1016/j.envint.2014.03.004. 
499 from an old landfill over different time-scales. Eur. J. Soil Sci. 64, 16-26. DOI DOI: $500 \quad 10.1111 /$ ejss.12004.

501

502 Scire J.S., Strimaitis D.G., Yamartino R.J., Zhang X., 2000. A user's guide for the CALPUFF 503 dispersion model (Version 5), Earth Technology Inc., Concord.

504

505 Schauberger G., Piringer M., Schmitzer R., Kamp M., Sowa A., Koch R., Eckhof W., Grimm E., 506 Kypke J., Hartung E., 2012. Concept to assess the human perception of odour by estimating 507 short-time peak concentrations from one-hour mean values. Reply to a comment by Muller et al. 508 Atmos. Environ. 54, 624-628.

510 Sironi S., Capelli L., Centola P., Del Rosso R., Il Grande M., 2005. Odour emission factors for assessment and prediction of Italian MSW landfills odour impact. Atmos. Environ. 39, 53875394. DOI 10.1016/j.atmosenv.2005.05.023.

514 Sironi S., Capelli L., Del Rosso R., 2014. Odor Emissions. Reference Module in Chemistry, 515 Molecular Sciences and Chemical Engineering, Elsevier Inc.

517 Sohn J.H., Smith R., Yoong E., Leis J., Galvin G., 2003. Quantification of odours from piggery 518 effluent ponds using an electronic nose and an artificial neural network. Biosyst. Eng. 86, 399519 410. DOI http://dx.doi.org/10.1016/j.biosystemseng.2003.09.003.

521 Stordeur R.T., Stordeur C.M., Levine S.P., Hoggatt J.H., 1981. A new microprocessor-controlled 522 dynamic olfactometer. J. Air Waste Manage. 31, 377-380. DOI 10.1080/00022470.1981.10465232. 
525 Tieleman, H.W., 2008. Strong wind observations in the atmospheric surface layer. J. Wind Eng. 526 Ind. Aerod. 96, 41-77. DOI 10.1016/j.jweia.2007.03.003.

528 VDI, 2011. Olfactometry Static Sampling, VDI 3880, Dusseldorf.

529

530 Ying D., Chuanyu C., Bin H., Yueen X., Xuejuan Z., Yingxu C., Weixiang W., 2012.

531 Characterization and control of odorous gases at a landfill site: A case study in Hangzhou, China. 532 Waste Manage. 32, 317-326. DOI 10.1016/j.wasman.2011.07.016. 
$534 \quad$ FIGURES

535

536 Figure 1:

537

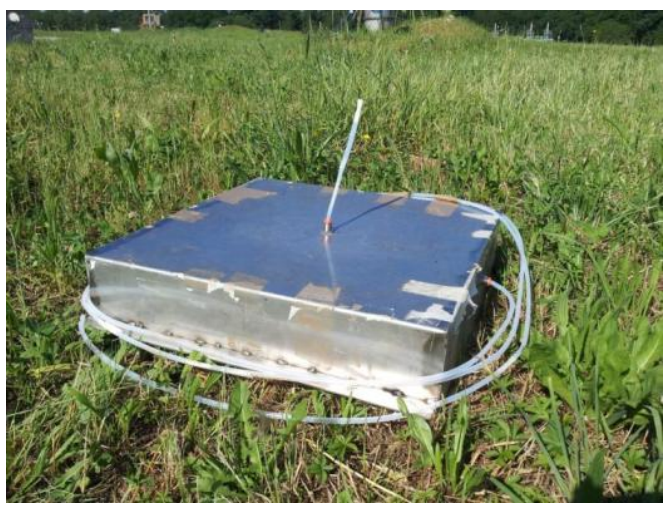

538

539 Figure 2:

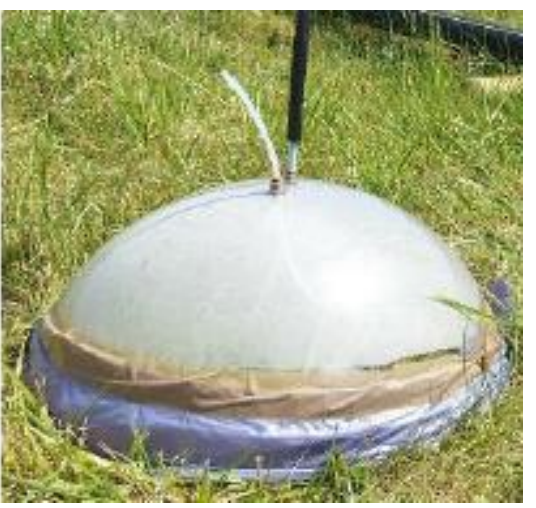

541

542 Figure 3: 

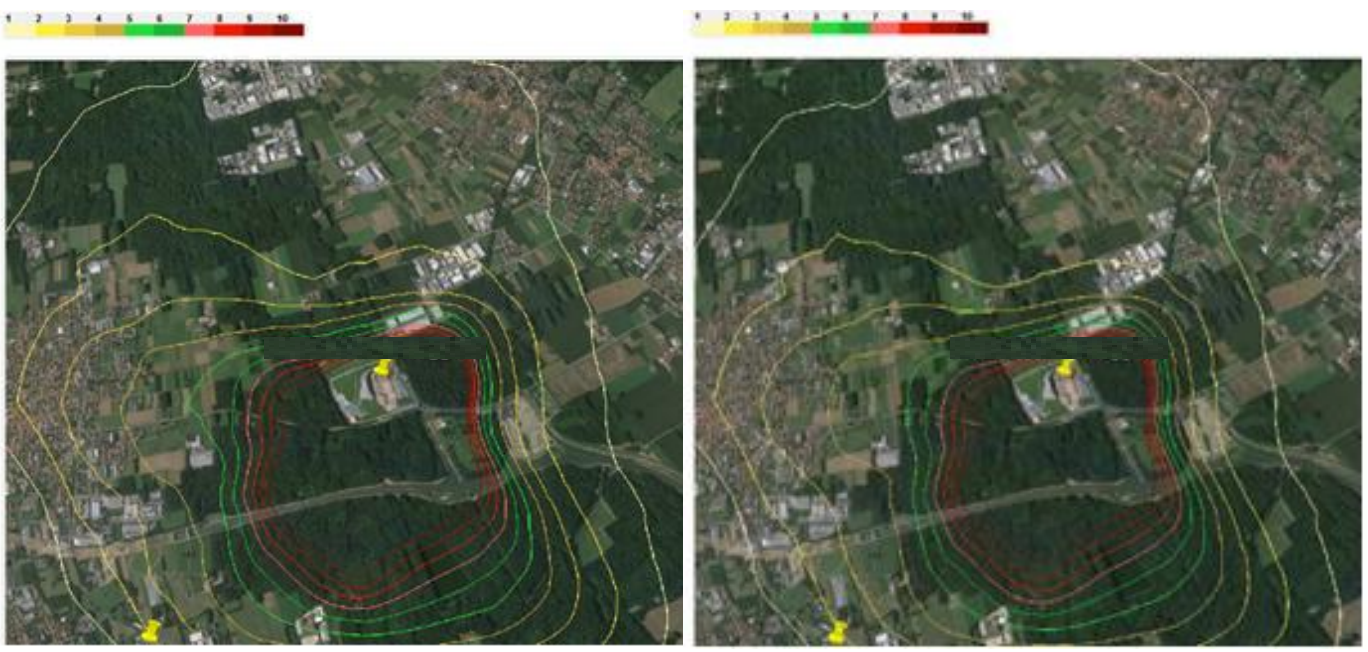

544

545

$546 \quad$ Figure 4:
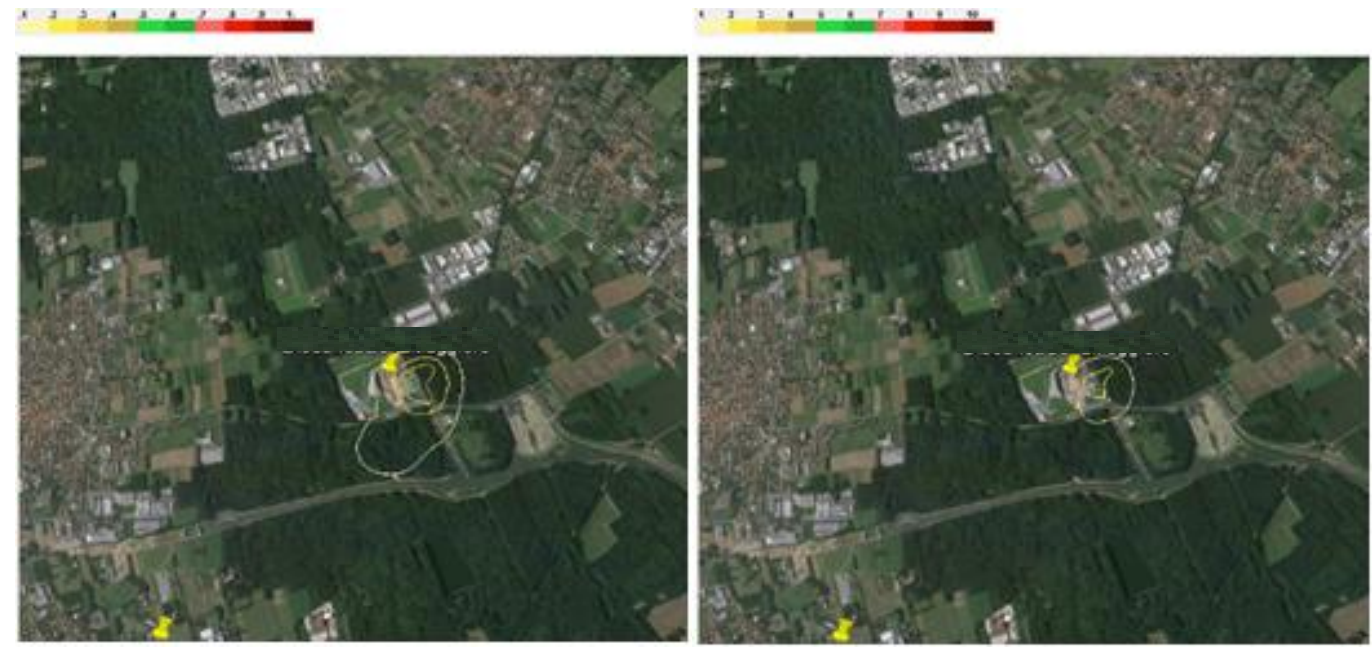

548

549 Figure 5:
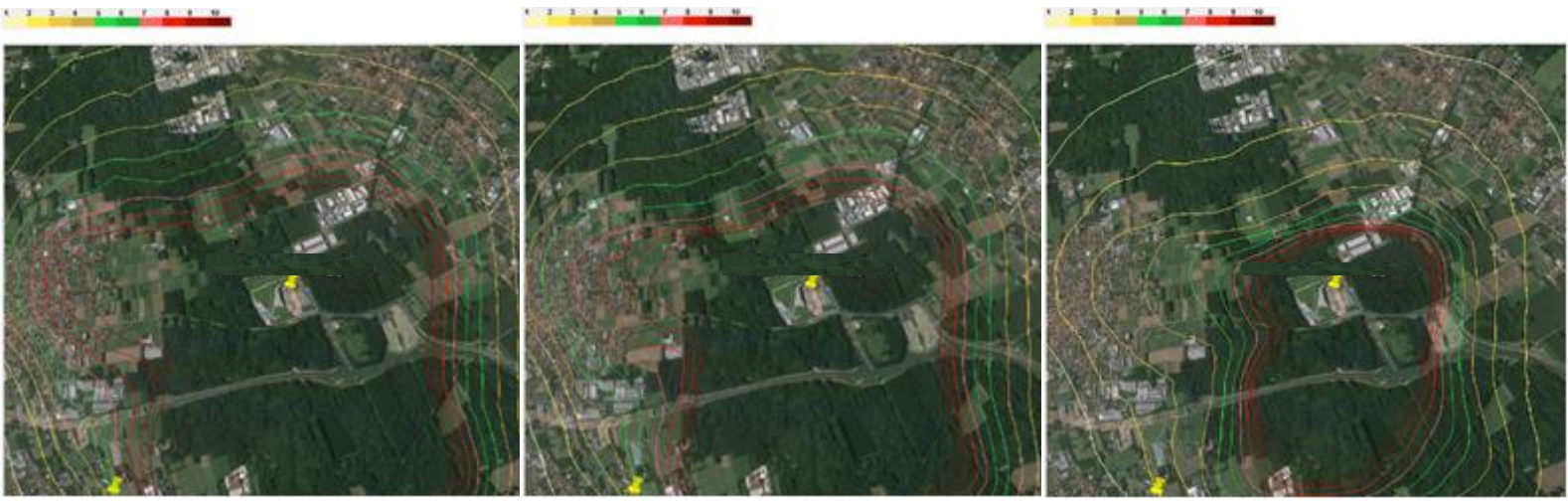
Highlights

1 Highlights for the article ( $<85$ characters/highlight):

2

3

- Odour emission assessment from landfills is important for landfill operation and management.

4

- Different methods for the evaluation of odour emissions from landfills were inspected.

5

- A new LandGEM-like software was developed for LFG generation assessment.

6

- One main outcome is that experimental campaigns on site are fundamental for emission assessment.

7

- Two sampling systems were designed and tested and the optimal sampling procedures were defined.

8

9 
1 Figure captions:

2

3 Figure 1. Static hood: picture of the static hood used for static sampling; design based on the ones

4 proposed by the UK EA and by Rachor.

5 Figure 2. Flux chamber: picture of the flux chamber used for fluxed sampling; design based on the 6 US EPA guidelines.

7 Figure 3. Odour dispersion modelling results A: Odour impacts predicted with methods 1 (left) and 82 (right).

9 Figure 4. Odour dispersion modelling results B: Odour impacts predicted with methods 3 (left) and 104 (right).

11 Figure 5. Odour dispersion modelling results C: Odour impacts predicted with methods 5 (left), 6 12 (centre) and 7 (right). 